\title{
The Van Y DD-carboxypeptidase of Enterococcus faecium BM4339 is a penicillin-binding protein
}

\author{
Peter E. Reynolds, ${ }^{1}$ O. Herman Ambur, ${ }^{1}$ Barbara Casadewall ${ }^{2}$ \\ and Patrice Courvalin ${ }^{2}$
}

Author for correspondence: Peter E. Reynolds. Tel: +44 1223 333644. Fax: +44 1223333345.

e-mail: per@mole.bio.cam.ac.uk

\footnotetext{
1 Department of Biochemistry, University of Cambridge, Tennis Court Road, Cambridge CB2 1QW, UK

2 Unité des Agents Antibactériens, Institut Pasteur, 28 rue du $\mathrm{Dr}$ Roux, 75724 Paris, Cedex 15, France
}

\begin{abstract}
VanD-type Enterococcus faecium BM4339 is constitutively resistant to vancomycin and to low levels of teicoplanin. This strain produces peptidoglycan precursors terminating in D-lactate but, unlike VanA- and VanBtype strains, E. faecium BM4339 has a mutated ddI ligase gene and cannot synthesize D-Ala-D-Ala. Consequently, although it possesses van $X_{D}$ and van $Y_{D}$ genes, it should not require an active VanX-type DD-dipeptidase or a VanY-type DD-carboxypeptidase for resistance. The van $Y_{D}$ gene contains the signatures of a penicillin-binding protein (PBP) and is believed to encode a penicillinsensitive DD-carboxypeptidase. The enzyme activity was found to be membrane-bound and inhibited by low concentrations of benzylpenicillin in membrane preparations and in intact bacteria, indicating that the active site was present on the outside surface of the membrane. The $\mathbf{3 8} \mathrm{kDa}$ protein was revealed as a PBP present in more copies per cell than conventional PBPs and all the protein was accessible to benzylpenicillin added externally, confirming the localization of the active site. A glycopeptide-susceptible strain of $E$. faecium lacked this PBP, and the membrane-bound DD-carboxypeptidase activity was less than $5 \%$ of that of $E$. faecium BM4339. Although the active site of Van $Y_{D}$ was external to the membrane, UDP-MurNAC-tetrapeptide was produced internally, probably from UDP-MurNAc-pentadepsipeptide. The presence of benzylpenicillin at low concentrations in the growth medium substantially reduced the amount of tetrapeptide produced, indicating that inhibition of $\operatorname{Van}_{\mathrm{D}}$ by benzylpenicillin influenced production of peptidoglycan precursors internally. A model to explain these contrasting observations is proposed.
\end{abstract}

Keywords: glycopeptide resistance, VanD phenotype, membrane-bound DD-peptidase, vancomycin resistance

\section{INTRODUCTION}

Glycopeptide antibiotics interfere with the last steps of peptidoglycan synthesis in Gram-positive bacteria (Nagarajan, 1991). These large molecules, which cannot penetrate the cytoplasmic membrane, form complexes with the C-terminal D-alanyl-D-alanine (D-Ala-D-Ala) of late peptidoglycan precursors when they are transported to the external side of the membrane (Reynolds, 1989). As a result, peptidoglycan precursors can no longer be incorporated into nascent peptidoglycan through the

Abbreviation: PBP, penicillin-binding protein. transglycosylation and the transpeptidation reactions. Release of the C-terminal D-Ala residue from pentapeptides, catalysed by penicillin-binding proteins (PBPs) displaying transpeptidase or DD-carboxypeptidase activity, is also inhibited (Arthur et al., 1996).

Enterococci with acquired VanA-, VanB- or VanD-type resistance to glycopeptides synthezise modified peptidoglycan precursors, ending in the depsipeptide $\mathrm{D}$-alanylD-lactate (D-Ala-D-Lac) instead of the dipeptide D-AlaD-Ala (Arthur et al., 1996). These modified precursors exhibit a 1000-fold reduced affinity for vancomycin (Bugg et al., 1991).

VanD-type resistance to glycopeptides in enterococci is 
mediated by the chromosomal vanD gene cluster, which includes at least six open reading frames (Casadewall \& Courvalin, 1999; Périchon et al., 2000). The $5^{\prime}$ region of the $v a n D$ operon contains the $v a n R_{D}$ and $v a n S_{D}$ genes encoding a two-component regulatory system. The van $Y_{D}$ gene, located downstream, encodes a DDcarboxypeptidase related to PBPs (Casadewall \& Courvalin, 1999). The $3^{\prime}$ part of the vanD gene cluster includes the $v a n H_{D}, v a n D$ and $v a n X_{D}$ genes, which encode a D-Lac dehydrogenase, a D-Ala:D-Lac ligase and a DD-dipeptidase, respectively. These proteins are homologous to the corresponding enzymes in VanAand VanB-type strains.

VanD-type Enterococcus faecium BM4339 is constitutively resistant to moderate levels of vancomycin (MIC $64 \mu \mathrm{g} \mathrm{ml}^{-1}$ ) and to low levels of teicoplanin (MIC $4 \mu \mathrm{g} \mathrm{m}^{-1}$ ) (Périchon et al., 1997). In this strain, the vanD gene cluster contains, at the $3^{\prime}$ end, the int $D$ gene, which encodes an integrase-like protein (Casadewall et al., 2001). The $\operatorname{van} Y_{D}$ gene is co-transcribed with $v_{a n} H_{D}$, vanD, van $X_{D}$ and intD from the $P_{Y D}$ promoter, whereas the $v a n R_{D}$ and $v a n S_{D}$ genes are expressed from the $P_{R D}$ promoter (Casadewall et al., 2001). Due to a frameshift mutation in the chromosomal $d d l$ gene (Casadewall \& Courvalin, 1999), E. faecium BM4339 produces an impaired D-Ala:D-Ala ligase (Ddl), accounting for the lack of D-Ala-D-Ala-terminating peptidoglycan precursors in this strain (Périchon et al., 1997).

VanY $Y_{D}$ DD-carboxypeptidase belongs to the PBP family of catalytic-serine enzymes which are susceptible to benzylpenicillin (Joris et al., 1988), whereas VanY and $V_{\text {an }} \mathrm{B}_{\mathrm{B}}$ from VanA- and VanB-type strains are penicillininsensitive $\mathrm{Zn}^{2+}$-dependent proteins (Arthur et al., 1998; Wright et al., 1992). In glycopeptide-resistant enterococci, both types of membrane-bound enzymes hydrolyse pentapeptide and/or pentadepsipeptide peptidoglycan precursors to tetrapeptides, but their catalytic efficiency depends on the substrate. Although some of the PBPs which function as DD-carboxypeptidases preferentially cleave depsipeptide substrates (Rasmussen \& Strominger, 1978), the $\mathrm{Zn}^{2+}$-dependent VanY DD-carboxypeptidase exhibits a higher catalytic efficiency for hydrolysis of substrates ending in D-Ala-DAla (Arthur et al., 1998). VanY $Y_{B}$ has been shown to play a more important role in VanB-type resistance than VanY in VanA-type resistance (Reynolds, 1998). VanY ${ }_{B}$ contributes to resistance by hydrolysing pentapeptide precursors rapidly after induction by vancomycin, whereas, in VanA-type strains, the high D-Ala-D-Ala dipeptidase activity of VanX is sufficient for resistance (Arthur et al., 1994).

To characterize the $V_{a n} Y_{D}$ PBP, we have studied the binding of benzyl $\left[{ }^{14} \mathrm{C}\right]$ penicillin to $\operatorname{VanY}_{\mathrm{D}}$ in intact cells and in membrane preparations of E. faecium BM4339. To determine the role of the $V_{a n Y} Y_{D}$ DDcarboxypeptidase activity in glycopeptide resistance in E. faecium BM4339, we have investigated the effect of treatment of intact bacteria and membrane preparations with benzylpenicillin on enzymic activity. The results suggest an extracytoplasmic localization of the active site of $\operatorname{VanY}_{\mathrm{D}}$ and we propose a model to account for the presence of tetrapeptide in the cytoplasm of $E$. faecium BM4339.

\section{METHODS}

Strains and growth conditions. Glycopeptide-resistant E. faecium BM4339 (Périchon et al., 1997) and glycopeptidesusceptible E. faecium ATCC 9790 were grown in brain heart infusion (BHI) broth or on BHI agar supplemented with yeast extract $(0.5 \%, \mathrm{w} / \mathrm{v})(\mathrm{BHY})$. Small culture volumes were incubated overnight at $30^{\circ} \mathrm{C}$. The cultures were diluted in BHY broth to an $\mathrm{OD}_{600}$ less than $0 \cdot 1$ and incubated in an orbital incubator $\left(100\right.$ r.p.m.) at $37^{\circ} \mathrm{C}$. Cultures were used in the exponential phase of growth $\left(\mathrm{OD}_{600} 0 \cdot 8-1 \cdot 0\right)$. The MICs of antibiotics were determined using twofold dilutions of the antibiotics in BHY broth with an inoculum of $10^{6}$ bacteria $\mathrm{ml}^{-1}$. Tubes were incubated for $24 \mathrm{~h}$ at $37^{\circ} \mathrm{C}$.

Analysis of precursors. Extraction and analysis of soluble peptidoglycan precursors were carried out essentially as described previously (Arthur et al., 1998). Ramoplanin was used at a final concentration of $3 \mu \mathrm{g} \mathrm{m}^{-1}$ for $15 \mathrm{~min}$ to eliminate possible damage to the cytoplasmic membrane during accumulation of the precursors. After extraction with trichloroacetic acid and desalting on Sephadex G10, HPLC was used to separate the late peptidoglycan precursors and the relative amounts were determined from the integrated peak areas (Arthur et al., 1998).

Preparation of membrane fragments. A $20 \mathrm{ml}$ culture at an $\mathrm{OD}_{600}$ of 1.0 was centrifuged $(25000 \mathrm{~g}, 30 \mathrm{~s})$, the pellet washed once in $50 \mathrm{mM}$ Tris/ $\mathrm{HCl} \mathrm{pH} 7.2$ and the cells resuspended in $0.9 \mathrm{ml}$ of the same buffer. Then $100 \mu \mathrm{l}$ lysozyme $\left(4 \mathrm{mg} \mathrm{ml}^{-1}\right)$ and $70 \mu \mathrm{l} \mathrm{M} 1$ muramidase $\left(1 \mathrm{mg} \mathrm{ml}^{-1}\right)$ were added and the mixture incubated at $37^{\circ} \mathrm{C}$ until osmotic lysis was complete as judged by clearing of the suspension and phase-contrast microscopy. DNase $\left(25 \mu \mathrm{g} \mathrm{ml}^{-1}\right)$ and $\mathrm{MgCl}_{2}(5 \mathrm{mM})$ were added and incubation continued for $3 \mathrm{~min}$ at $37^{\circ} \mathrm{C}$. The suspension was cooled to $4{ }^{\circ} \mathrm{C}$ and the membrane fraction collected by centrifugation at $48000 \mathrm{~g}$ for $20 \mathrm{~min}$. The pellet was washed in $50 \mathrm{mM}$ Tris $/ \mathrm{HCl} \mathrm{pH7.2} \mathrm{and} \mathrm{finally}$ resuspended in the same buffer.

\section{Binding of benzyl[ $\left[{ }^{14} \mathrm{C}\right]$ penicillin}

Membrane labelling. Ten microlitres of a membrane suspension $\left(5 \mathrm{mg}\right.$ protein $\mathrm{ml}^{-1}$ ) was incubated for $5 \mathrm{~min}$ at $37^{\circ} \mathrm{C}$ with $2 \mu \mathrm{l}$ of different concentrations of benzyl $\left[{ }^{14} \mathrm{C}\right]$ penicillin $\left(53 \mathrm{mCi} \mathrm{mmol}^{-1}\right.$; $\left.1961 \mathrm{MBq} \mathrm{mmol}^{-1}\right)$. Then $2 \mu \mathrm{l}$ unlabelled penicillin $\left(3 \mathrm{mg} \mathrm{ml}^{-1}\right)$ was added and membrane proteins were solubilized by heating for $4 \mathrm{~min}$ at $98^{\circ} \mathrm{C}$ after addition of Sample Buffer (New England Biolabs). The proteins were separated by SDS-PAGE on a $12 \%$ polyacrylamide gel using the Laemmli buffer system (Laemmli, 1970). The gel was stained with $0.1 \%$ Coomassie blue in $50 \%(\mathrm{v} / \mathrm{v})$ methanol $/ 10 \%(\mathrm{v} / \mathrm{v})$ acetic acid for $30 \mathrm{~min}$ at $37^{\circ} \mathrm{C}$, destained with $10 \%(\mathrm{v} / \mathrm{v})$ methanol $/ 10 \%(\mathrm{v} / \mathrm{v})$ acetic acid for $1 \mathrm{~h}$ at $37^{\circ} \mathrm{C}$ and dried on $3 \mathrm{MM}$ paper using a Hoefer slab gel drier. PBPs were detected and the amounts of the $40-42 \mathrm{kDa}$ penicilloyl-protein complex determined using a phosphorimager (Molecular Dynamics, model 425). Autoradiography on Kodak X-Omat film was carried out for 4 weeks to reveal minor PBPs.

Intact cell labelling. Bacteria were harvested, washed once in $50 \mathrm{mM}$ Tris/ $\mathrm{HCl} \mathrm{pH} \mathrm{7.2} \mathrm{and} \mathrm{resuspended} \mathrm{at} 10 \mathrm{mg}$ dry wt ml-1. Aliquots of $50 \mu \mathrm{l}$ were incubated with benzyl $\left[{ }^{14} \mathrm{C}\right]$ penicillin for $5 \mathrm{~min}$ at $37^{\circ} \mathrm{C}$. The samples were diluted 10 -fold in $50 \mathrm{mM}$ Tris/ $\mathrm{HCl}$ pH $7 \cdot 2$ containing 
unlabelled benzylpenicillin $\left(2 \mathrm{mg} \mathrm{ml}^{-1}\right)$ and lysed by treatment with lysozyme $\left(400 \mu \mathrm{g} \mathrm{ml}^{-1}\right)$ and $\mathrm{M} 1$ muramidase $\left(70 \mu \mathrm{g} \mathrm{ml}^{-1}\right)$. Membranes were pelleted by centrifugation $(48000 \mathrm{~g}, 20 \mathrm{~min})$, washed once and resuspended in $10 \mu \mathrm{l} 50 \mathrm{mM}$ Tris $/ \mathrm{HCl} \mathrm{pH}$ 7·2. Membrane proteins were separated and PBPs determined as described above.

Accessibility of DD-carboxypeptidase in intact bacteria. Bacteria were harvested, washed once and resuspended at $2 \mathrm{mg}$ dry wt $\mathrm{ml}^{-1}$ in $50 \mathrm{mM}$ Tris/ $\mathrm{HCl} \mathrm{pH} 7 \cdot 2$. Aliquots $(0 \cdot 5 \mathrm{ml})$ were incubated with benzylpenicillin $\left(1,0 \cdot 1\right.$ and $\left.0.01 \mu \mathrm{g} \mathrm{ml}^{-1}\right)$ for $5 \mathrm{~min}$ at $37^{\circ} \mathrm{C}$, a large excess of $\beta$-lactamase (Neutrapen, Riker laboratories), 20000 units, was added and incubation continued for $1 \mathrm{~min}$ at $37^{\circ} \mathrm{C}$. The samples were diluted with $5 \mathrm{ml} 50 \mathrm{mM}$ Tris $/ \mathrm{HCl} \mathrm{pH7 \cdot 2}$ at $4{ }^{\circ} \mathrm{C}$ and the bacteria harvested by centrifugation at $25000 \mathrm{~g}$ for $30 \mathrm{~s}$. The pellet was resuspended in $5 \mathrm{ml}$ of the same buffer and the centrifugation stage repeated. The bacterial pellet was resuspended in $0.5 \mathrm{ml}$ Tris $/ \mathrm{HCl} \mathrm{pH} \mathrm{7.2} \mathrm{containing} \mathrm{lysozyme}(200 \mu \mathrm{g})$ and $\mathrm{M} 1$ muramidase $(35 \mu \mathrm{g})$ and incubated at $37^{\circ} \mathrm{C}$ until lysis was complete $(15 \mathrm{~min})$. DNase $\left(25 \mu \mathrm{g} \mathrm{ml}^{-1}\right)$ and $5 \mathrm{mM} \mathrm{MgCl}_{2}$ were added and incubation continued for $3 \mathrm{~min}$. The membrane suspension was cooled to $4{ }^{\circ} \mathrm{C}$ and the membranes collected by centrifugation at $48000 \mathrm{~g}$ for $20 \mathrm{~min}$. The pellets were resuspended in $250 \mu \mathrm{l} 50 \mathrm{mM}$ Tris $/ \mathrm{HCl} \mathrm{pH} \mathrm{7.2} \mathrm{and} \mathrm{DD-}$ carboxypeptidase activity determined using $10 \mu \mathrm{l}$ samples in duplicate.

\section{Assay of DD-carboxypeptidase activity}

Determination of D-Ala released. This was carried out essentially as described previously (Messer \& Reynolds, 1992). A membrane preparation $\left(10 \mu \mathrm{l}, 0 \cdot 8 \mathrm{mg}\right.$ protein $\left.\mathrm{ml}^{-1}\right)$ was incubated in $50 \mathrm{mM}$ Tris/ $\mathrm{HCl} \mathrm{pH} \mathrm{7.2} \mathrm{with} 10 \mathrm{mM}$ pentapeptide for $30 \mathrm{~min}$ at $37^{\circ} \mathrm{C}$. D-Ala released from the substrate was determined using $\mathrm{D}$-amino acid oxidase with $o$-dianisidine as the chromogen.

Determination of UDP-MurNAc-tetrapeptide. A membrane preparation $\left(10 \mu \mathrm{l}, 2 \mathrm{mg}\right.$ protein $\left.\mathrm{ml}^{-1}\right)$ was incubated in $50 \mathrm{mM}$ Tris $/ \mathrm{HCl} \mathrm{pH} 7.2$ with $3.5 \mathrm{mM}$ pentapeptide or pentadepsipeptide for $30 \mathrm{~min}$ at $37^{\circ} \mathrm{C}$. Proteins were removed by treatment with 5-sulphosalicylic acid, the supernatant diluted 35 -fold to give a $100 \mu \mathrm{M}$ solution of nucleotide precursors and the tetrapeptide product separated from the substrate by HPLC (Reynolds et al., 1999).

\section{RESULTS}

\section{Glycopeptide resistance and penicillin action}

E. faecium BM4339, in common with other E. faecium strains, was resistant to benzylpenicillin, with an MIC of

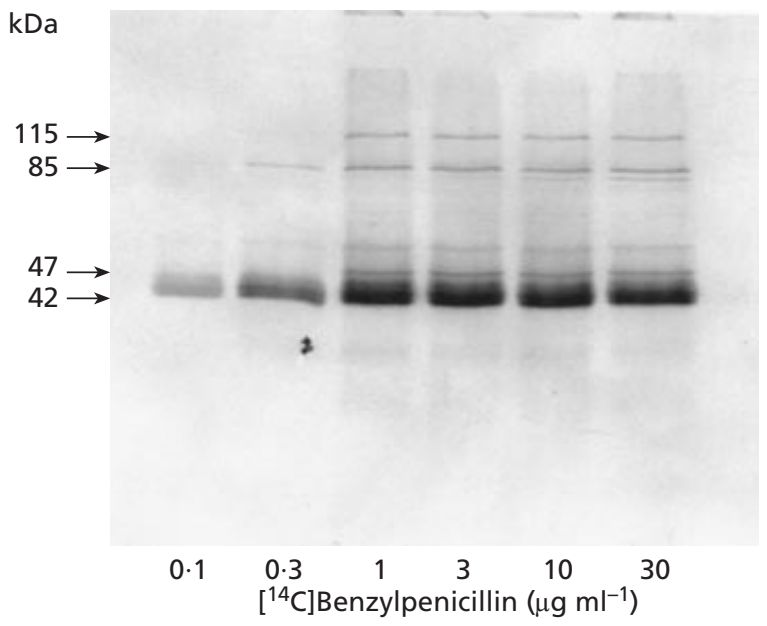

Fig. 1. Binding of benzyl$\left[{ }^{14} \mathrm{C}\right]$ penicillin to membrane proteins of E. faecium BM4339. A membrane preparation was incubated with various concentrations of benzyl[ $\left.{ }^{14} \mathrm{C}\right]$ penicillin for $5 \mathrm{~min}$ at $37^{\circ} \mathrm{C}$. Membrane proteins were separated by SDS-PAGE on a $12 \%$ polyacrylamide gel. The gel was stained with Coomassie blue, destained, dried and PBPs revealed by autoradiography.

$128 \mu \mathrm{g} \mathrm{ml}^{-1}$. It does not produce a $\beta$-lactamase, indicating that a PBP vital for peptidoglycan metabolism was not saturated at this antibiotic concentration. The MIC of vancomycin was $64 \mu \mathrm{g} \mathrm{ml}^{-1}$. However, the two antibiotics acted synergistically and no growth occurred when benzylpenicillin was present at $2 \mu \mathrm{g} \mathrm{ml}^{-1}$ and

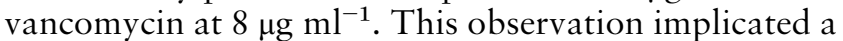
penicillin-binding protein in the glycopeptide resistance mechanism of E. faecium BM4339. Synergism between penicillins and glycopeptides has already been observed in VanA-type enterococci and was accounted for by processing of D-Ala-D-Lac-ending precursors by a conventional PBP with high affinity for $\beta$-lactams (Gutmann et al., 1994).

\section{Effect of growth in the presence of benzylpenicillin on peptidoglycan precursors}

UDP-MurNAc-L-Ala-D-Glu-L-Lys-D-Ala (tetrapeptide) is present in the cytoplasm of E. faecium BM4339 after a 15 min incubation with ramoplanin, which inhibits the

Table 1. Effect of benzylpenicillin on peptidoglycan precursors of $E$. faecium BM4339 and BM4458 [BM4339::pAT665 $\left.\left(P_{2} d d l\right)\right]$

\begin{tabular}{|ccccc|}
\hline Strain & $\begin{array}{c}\text { Benzylpenicillin in } \\
\text { growth medium } \\
\left(\boldsymbol{\mu} \mathrm{g} \mathrm{m}^{-1}\right)\end{array}$ & Tetrapeptide & Pentapeptide & Pentadepsipeptide \\
\cline { 3 - 5 } & 0 & 22 & 2 & 76 \\
BM4339 & $0 \cdot 1$ & 6 & 4 & 90 \\
& $1 \cdot 0$ & 3 & 8 & 89 \\
& 10 & 0 & 7 & 93 \\
BM4458 & 0 & 54 & 6 & 40 \\
& $1 \cdot 0$ & 1 & 35 & 64 \\
\hline
\end{tabular}




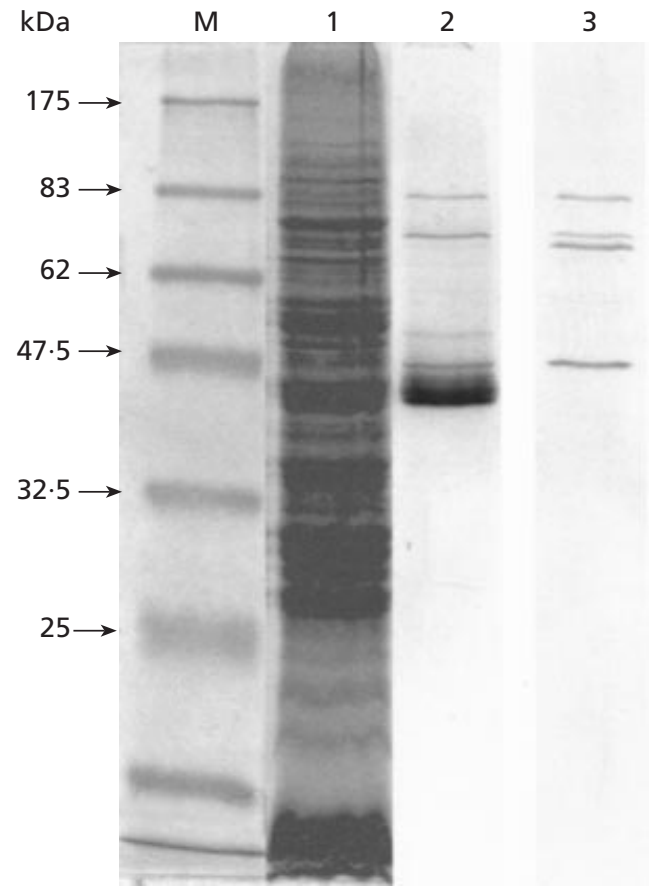

Fig. 2. The PBPs of E. faecium BM4339 and glycopeptidesusceptible $E$. faecium ATCC 9790 . Membranes were incubated with benzyl[ $\left.{ }^{14} \mathrm{C}\right]$ penicillin, the membrane proteins separated and PBPs revealed as in the legend for Fig. 1. Lane M, protein standards; lane 1, Coomassie-stained membrane proteins of $E$. faecium BM4339; lane 2, PBPs of E. faecium BM4339; lane 3, PBPs of $E$. faecium ATCC 9790.

transfer of GlcNAc from UDP-GlcNAc to C-55 undecaprenyl-P-P-MurNAc(pentapeptide) (lipid I) to produce lipid II (Somner \& Reynolds, 1990). The DDcarboxypeptidase activity believed to be catalysed by $V_{\text {an }} \mathrm{D}_{\mathrm{D}}$ is inhibited by benzylpenicillin (Périchon et al., 1997). If this enzyme is involved in the production of tetrapeptide in the cytoplasm, growth of E. faecium BM4339 in the presence of penicillin G followed by analysis of the precursors would be expected to result in a reduction of the amount of tetrapeptide produced. Low concentrations of benzylpenicillin in the growth medium caused the predicted reduction in tetrapeptide (Table 1). The effect of benzylpenicillin was more marked in E. faecium BM4458 [BM4339:: pAT665 $\left.\left(P_{2} d d l\right)\right]$. This strain synthesizes pentapeptide and pentadepsipeptide precursors, but both the amount and percentage of pentapeptide increased substantially when benzylpenicillin $\left(1 \mu \mathrm{g} \mathrm{ml}^{-1}\right)$ was included in the growth medium (Table 1), indicating that it was almost totally hydrolysed when $\operatorname{VanY}_{\mathrm{D}}$ was active.

\section{Analysis of PBPs of E. faecium BM4339 and glycopeptide-susceptible $E$. faecium ATCC 9790}

Incubation of a membrane preparation with various concentrations of benzyl $\left[{ }^{14} \mathrm{C}\right]$ penicillin indicated that $E$. faecium BM4339 contained a PBP which migrated as a
Table 2. Binding of benzyl $\left[{ }^{14} \mathrm{C}\right]$ penicillin to the 40-42 kDa protein doublet in membranes of E. faecium BM4339

Intact bacteria were labelled, unbound benzyl $\left[{ }^{14} \mathrm{C}\right]$ penicillin was destroyed and membrane fractions were prepared. The values shown are the means of two experiments.

\begin{tabular}{|lcc|}
\hline \multirow{2}{*}{$\begin{array}{c}\text { Benzyl }\left[{ }^{14} \mathrm{C}\right] \text { penicillin } \\
\end{array}$} & \multicolumn{2}{c|}{ Percentage bound } \\
\cline { 2 - 3 } & $\begin{array}{c}\text { Membrane } \\
\text { preparation }\end{array}$ & $\begin{array}{c}\text { Intact } \\
\text { bacteria }\end{array}$ \\
\hline 30 & {$[100]$} & \\
10 & 94 & {$[100]$} \\
3 & 100 & 100 \\
1 & 99 & 93 \\
$0 \cdot 3$ & 44 & 71 \\
$0 \cdot 1$ & 14 & 25 \\
$0 \cdot 03$ & 2 & 4 \\
\hline
\end{tabular}

doublet on SDS gels with an apparent molecular mass of 40-42 $\mathrm{kDa}$. The protein was more heavily labelled than the normal complement of high- and low- $M_{\mathrm{r}}$ PBPs involved in peptidoglycan metabolism and was saturated at low concentrations of benzylpenicillin (Fig. 1). The 40-42 kDa PBP was absent from membranes of $E$. faecium ATCC 9790 (Fig. 2). The protein was accessible to benzyl $\left[{ }^{14} \mathrm{C}\right]$ penicillin at low concentrations in intact bacteria and the $50 \%$ saturation level was similar to that obtained with binding to membrane preparations (Table 2). The penicilloyl-protein bond was stable but in a $4 \mathrm{~h}$ incubation at $37^{\circ} \mathrm{C}$ the complex was degraded to a $32 \mathrm{kDa}$ penicilloylpeptide that was no longer membrane bound, indicating that the membrane-spanning domain had been removed (result not shown). Previous growth of the bacteria in the presence of unlabelled benzylpenicillin $\left(3 \mu \mathrm{g} \mathrm{ml}^{-1}\right)$ completely saturated the $40-$ $42 \mathrm{kDa} \mathrm{PBP}$, as rigorous washing of the bacteria followed by preparation of the membrane fraction and incubation with benzyl $\left[{ }^{14} \mathrm{C}\right]$ penicillin $\left(10 \mu \mathrm{g} \mathrm{ml}{ }^{-1}\right)$ resulted in less than $1 \%$ radioactivity bound to the protein relative to that in the control preparation obtained from bacteria grown in the absence of benzylpenicillin.

\section{Inhibition of DD-carboxypeptidase activity by benzylpenicillin}

The DD-carboxypeptidase activity in membrane preparations of E. faecium BM4339 was inhibited by low concentrations of benzylpenicillin with an $\mathrm{ID}_{50}$ of approximately $0.02 \mu \mathrm{g} \mathrm{ml}^{-1}$ (Table 3 ). To investigate whether the activity was also inhibited by benzylpenicillin in intact bacteria, a washed suspension of $E$. faecium BM4339 was treated with different concentrations of the antibiotic followed by removal of unbound benzylpenicillin with $\beta$-lactamase and extensive washing prior to osmotic lysis of the bacteria and 
Table 3. Inhibition of VanY $Y_{D}$ DD-carboxypeptidase of $E$. faecium BM4339 by benzylpenicillin

The values shown are the mean of two determinations with preparations from different cultures.

\begin{tabular}{|c|c|c|}
\hline \multirow{2}{*}{$\begin{array}{l}\text { Benzylpenicillin } \\
\left(\mu \mathrm{g} \mathrm{ml}^{-1}\right)\end{array}$} & \multicolumn{2}{|c|}{ Inhibition (\%) } \\
\hline & $\begin{array}{l}\text { Membrane } \\
\text { preparation }\end{array}$ & $\begin{array}{c}\text { Intact } \\
\text { bacteria }\end{array}$ \\
\hline $0 \cdot 0045$ & 25 & \\
\hline $0 \cdot 01$ & & 0 \\
\hline $0 \cdot 015$ & 46 & \\
\hline 0.045 & 92 & \\
\hline $0 \cdot 1$ & & 61 \\
\hline $0 \cdot 15$ & 98 & \\
\hline $1 \cdot 0$ & 100 & 94 \\
\hline
\end{tabular}

assay of DD-carboxypeptidase activity in the resultant membrane preparation. The activity was inhibited at concentrations of benzylpenicillin similar to those that completely inhibited the enzyme in membrane preparations (Table 3). A control to investigate the breakdown of the DD-carboxypeptidase-penicillin complex at $37^{\circ} \mathrm{C}$ demonstrated that no activity was regained in the time taken to lyse the bacteria osmotically prior to recovery and washing of the membrane preparation. In a further control, membrane preparations from two glycopeptidesusceptible strains of E. faecium were assayed for DDcarboxypeptidase activity at the same concentration of membrane protein: less than $5 \%$ of the DD-carboxypeptidase activity of membranes from E. faecium BM4339 was present, indicating that the normal low- $M_{\mathrm{r}}$ PBPs of E. faecium BM4339 would not have contributed significantly to the release of D-Ala under the conditions of the experiment.

\section{Substrate specificity of Van $Y_{D}$ DD-carboxypeptidase}

The substrate specificity of membrane-bound Van $Y_{D}$ was investigated by following production of tetrapeptide from UDP-MurNAc-L-Ala-D-Glu-L-Lys-D-Ala-D-Ala (pentapeptide) or UDP-MurNAc-L-Ala-D-Glu-L-Lys-DAla-D-Lac (pentadepsipeptide) by HPLC. The activity of a membrane preparation of E. faecium BM4339 was more than threefold greater against pentapeptide than pentadepsipeptide and both activities were inhibited by benzylpenicillin (Table 4). The DD-carboxypeptidase activity of a membrane preparation of glycopeptidesusceptible E. faecium ATCC 9790 against pentapeptide was not detectable under the same conditions although low penicillin-susceptible activity was detected with pentadepsipeptide as substrate (Table 4).

\section{DISCUSSION}

Vancomycin resistance is expressed constitutively in $E$. faecium BM4339. A mutation in the $d d l$ gene results in a defective D-Ala:D-Ala ligase and the consequent absence of peptidoglycan precursors ending in D-Ala-D-Ala. The constitutive phenotype could be due to a mutation in the $v_{\text {van }} S_{D}$ gene (Casadewall \& Courvalin, 1999) or to the activity of a different protein kinase able to upregulate expression of the vanD gene cluster (Casadewall et al., 2001). The majority of E. faecium isolates grow in high concentrations of benzylpenicillin because the vital target of penicillin is a PBP with low affinity. However, growth of E. faecium BM4339 in the presence of subinhibitory concentrations of benzylpenicillin resulted in a substantial decrease of the vancomycin MIC, indicating that a penicillin-sensitive reaction was likely to be involved in glycopeptide resistance of this strain. The percentages of peptidoglycan precursors in the cytoplasm were also altered as a result of growth of BM4339 or BM4458 [BM4339::pAT665 $\left.\left(P_{2} d d l\right)\right]$ in the presence of benzylpenicillin, with a marked reduction in the amount of tetrapeptide present. This compound is produced as the result of DD-carboxypeptidase activity on pentapeptide or pentadepsipeptide precursors. These observations suggested that the active site of the penicillin-sensitive DD-carboxypeptidase was external to the cytoplasmic membrane because bacteria have been shown to be impermeable to benzylpenicillin (Cooper, 1956), but, in contrast, inhibition of its activity affected peptidoglycan precursors produced internally.

The location of the active site of $\operatorname{VanY}_{\mathrm{D}}$, the putative

Table 4. DD-Carboxypeptidase activity in E. faecium strains

Activities are expressed as nmol UDP-MurNAc-tetrapeptide produced $\min ^{-1}$ ( $\mathrm{mg}$ membrane protein $)^{-1}$. BPen, benzylpenicillin $100 \mu \mathrm{g} \mathrm{ml}^{-1}$.

\begin{tabular}{|c|c|c|c|c|c|c|}
\hline \multirow[t]{3}{*}{ Strain } & \multicolumn{6}{|c|}{ Substrate: } \\
\hline & \multicolumn{3}{|c|}{ UDP-Mur-NAc-pentapeptide } & \multicolumn{3}{|c|}{ UDP-MurNAc-pentadepsipeptide } \\
\hline & - BPen & + BPen & $\%$ inhibition & - BPen & + BPen & $\%$ inhibition \\
\hline BM4339 & $29 \cdot 6$ & $<0 \cdot 01$ & 100 & $8 \cdot 6$ & $0 \cdot 4$ & 96 \\
\hline ATCC 9790 & $\leqslant 0 \cdot 01$ & $\leqslant 0 \cdot 01$ & - & $3 \cdot 3$ & $\leqslant 0 \cdot 01$ & 100 \\
\hline
\end{tabular}


DD-carboxypeptidase, was investigated by two methods: binding of benzyl $\left[{ }^{14} \mathrm{C}\right]$ penicillin to intact bacteria and membrane preparations, and secondly, measurement of enzyme activity in membrane preparations after treatment of membranes or intact bacteria with benzylpenicillin. The PBP profile of membrane proteins in VanD E. faecium BM4339, but not the amounts of individual PBPs, was virtually identical to that of the glycopeptide-susceptible E. faecium ATCC 9790, with the exception that a heavily labelled protein doublet was also present with a mass of $40-42 \mathrm{kDa}$, lower than that of any of the conventional PBPs of E. faecium isolates. The $40-42 \mathrm{kDa}$ protein was saturated at a benzyl $\left[{ }^{14} \mathrm{C}\right]$ penicillin concentration of $1 \cdot 0 \mu \mathrm{g} \mathrm{ml}^{-1}$ both in membrane preparations, where binding could have occurred from either or both sides of the membrane, and after binding to intact bacteria, in which benzylpenicillin should bind only to active sites exposed on the outside surface of the cytoplasmic membrane. The lack of binding of benzyl $\left[{ }^{14} \mathrm{C}\right]$ penicillin to the $40-42 \mathrm{kDa}$ protein in membranes prepared from intact bacteria that had been grown in the presence of benzylpenicillin indicated that all the active sites of the protein were accessible to benzylpenicillin on the outside surface of the membrane. The amount of the $40-42 \mathrm{kDa}$ PBP, as judged by the amount of bound radiolabel, was severalfold greater than the amount of any of the PBPs common to both glycopeptide-susceptible and -resistant strains, consistent with the probability that this PBP is $\operatorname{VanY}_{D}$ and possesses DD-carboxypeptidase activity. The calculated $M_{\mathrm{r}}$ of $\mathrm{VanY}_{\mathrm{D}}$ is 38685 , smaller than that obtained by comparison of the rate of migration in SDS gels with those of standard proteins, but such measurements can lead to anomalous values. There was a reasonable correspondence between the concentrations of benzylpenicillin that bound to the $40-42 \mathrm{kD}$ a protein and those that inhibited DD-carboxypeptidase activity. Although the concentration of active benzylpenicillin in the radiolabelled preparation was assumed to be $100 \%$ of the value calculated on the basis of specific activity, freezing and thawing of the preparation over the course of several weeks would probably have resulted in some breakdown of the antibiotic, which would have affected the values given in Table 2 . If breakdown had occurred, the correspondence between the two sets of data in Tables 2 and 3 may have been closer than those obtained. Furthermore the enzyme activity of membranes prepared from bacteria that had been pretreated with benzylpenicillin prior to lysis and collection of the membrane fragments for assay was inhibited at concentrations similar to those that inhibited the activity when membranes were exposed directly to benzylpenicillin, confirming that the active site was external to the cytoplasmic membrane. In strains expressing the VanA and VanB phenotypes it had previously been concluded that the presence of tetrapeptide peptidoglycan precursors in the cytoplasm resulted from the activity of membrane-bound VanY or VanY ${ }_{B}$ in which the active site was inside the cytoplasmic membrane, although the substrate was most likely to be a lipid intermediate carrying the peptidoglycan subunit (Arthur et al., 1998).
The hydrophobicity profile of $\mathrm{Van}_{\mathrm{D}}$ suggests that, in common with high- $M_{\mathrm{r}}$ PBPs, there is a single transmembrane segment close to the $\mathrm{N}$-terminus. The penicillin-binding studies established that the tetrad motif SXXK containing the active-site serine is present external to the cytoplasmic membrane. This implies that the complete C-terminal domain of the protein that contains all the characteristic signatures of a PBP is present on the external face of the membrane.

Comparison of the DD-carboxypeptidase activities of membranes prepared from E. faecium BM4339 and from E. faecium ATCC 9790 provides strong evidence that the DD-carboxypeptidase activities measured in these investigations were catalysed by $\operatorname{VanY}_{\mathrm{D}}$ and not by another PBP. No DD-carboxypeptidase activity against pentapeptide was detected in the membranes of E. faecium ATCC 9790 by HPLC under the experimental conditions but a low level of activity against pentadepsipeptide was present, in agreement with the observations of Rasmussen \& Strominger (1978) that PBPs may have greater activity against esters than peptides. Membranes containing $V_{a n} Y_{D}$ possessed greater activity against pentapeptide than against pentadepsipeptide. Furthermore, a proportion of the activity against the latter substrate may have resulted from the activity of normal PBPs. In this respect, i.e. lower activity against esters than peptides, VanY $_{D}$ may differ from the classical PBPs though there is no obvious explanation for this difference. The fact that $\operatorname{VanY}_{\mathrm{D}}$ removes the terminal residue from both pentapeptide and pentadepsipeptide suggests that the tetrapeptide present in the cytoplasm following a short incubation with ramoplanin could have arisen from both precursors, though the amount of pentapeptide available as a substrate is likely to be small in view of the absence of an active D-Ala:D-Ala ligase. The small amount of pentapeptide present after growth of E. faecium BM4339 in the presence of benzylpenicillin could have resulted from the D-Ala:D-Ala ligase activity of VanD, which is assumed primarily to function as a D-Ala:D-Lac ligase (Casadewall \& Courvalin, 1999). Studies with BM4458 $\left[\mathrm{BM} 4339:: \mathrm{pAT} 665\left(P_{2} d d l\right)\right]$ confirmed that $\operatorname{VanY}_{\mathrm{D}}$ hydrolysed pentapeptide rapidly; the concentration of the precursor in the cytoplasm was reduced sixfold when the enzyme was active (Table 1).

It is difficult to explain how tetrapeptide, the product of the DD-carboxypeptidase reaction, is present inside the cell when the active site of the enzyme is on the outside surface of the cytoplasmic membrane. The peptidoglycan precursors were analysed after a $15 \mathrm{~min}$ incubation of the bacteria with ramoplanin (three times the MIC), which inhibits the conversion of lipid I to lipid II. As a result of the inhibition all the undecaprenyl lipid derivatives would be in the form of lipid I. The reaction in which P-MurNAc-pentapeptide is added to undecaprenyl lipid-P is reversible and the position of equilibrium in a non-dynamic situation favours the reverse reaction in which the nucleotide peptidoglycan precursor would be re-formed. If lipid I containing MurNAc-pentapeptide, when present in excess, could 


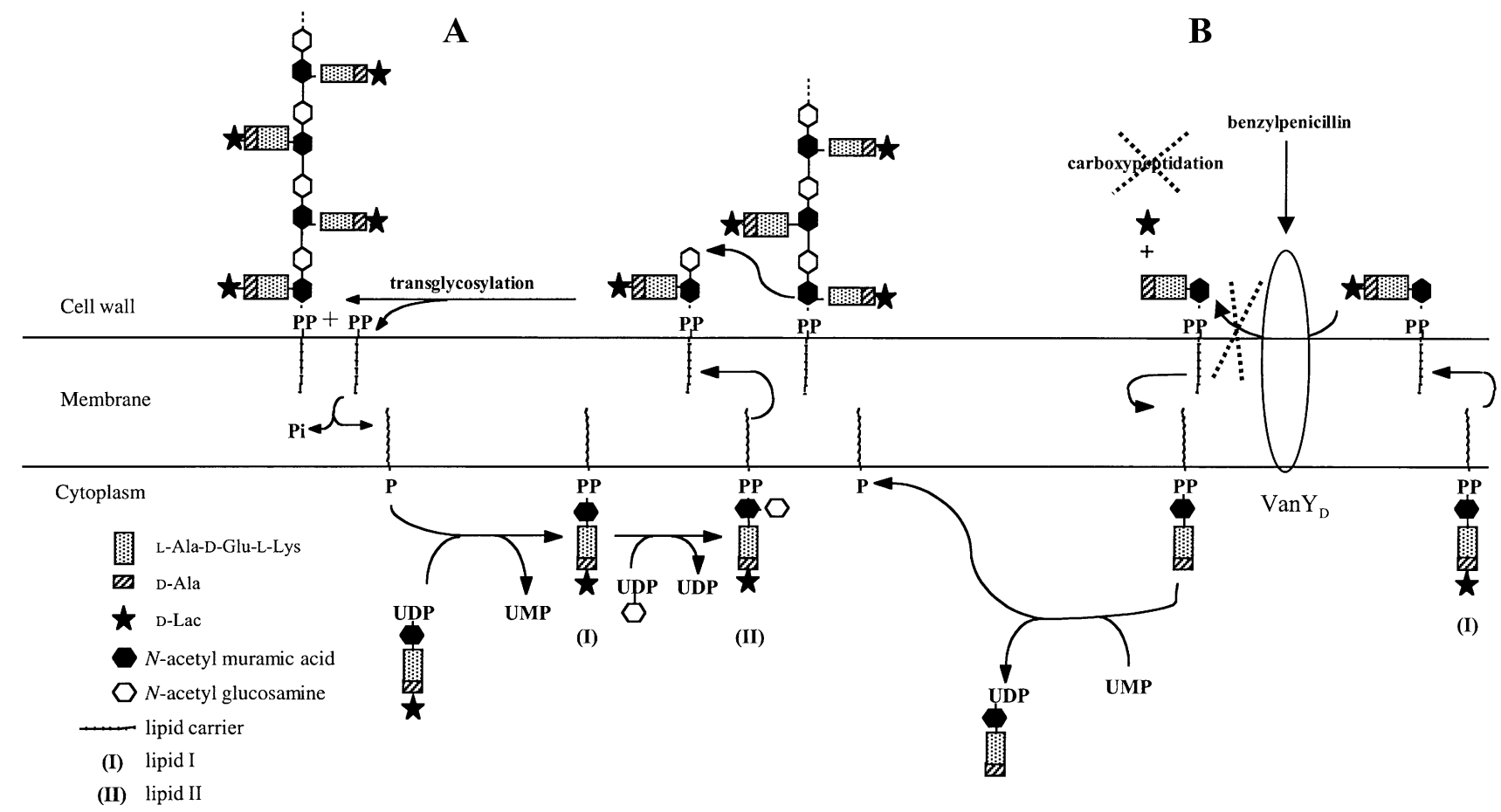

Fig. 3. Model to demonstrate the normal incorporation of MurNAc-pentadepsipeptide into peptidoglycan (A) and to explain how the activity of $V_{a n Y} Y_{D}$ with its active site on the outside surface of the membrane could catalyse the formation of UDP-MurNAc-tetrapeptide in the cytoplasm (B). Two key features of the model are the action of the enzyme UMP pyrophosphorylase, which catalyses the addition of P-MurNAc-pentapeptide to C-55 undecaprenylphosphate reversibly, and the assumption that lipid I (on the extreme right-hand side of the figure) can cross the membrane in both directions.

cross the membrane to the outside face (as does lipid II for peptidoglycan biosynthesis) it could be acted on by the $V_{\text {an }} \mathrm{D}_{\mathrm{D}}$ DD-carboxypeptidase to generate lipid I containing a tetrapeptide; the results suggest that this may be able to re-cross the membrane to the cytoplasm, where it could be acted on by UMP pyrophosphorylase to produce the tetrapeptide derivative (Fig. 3).

The location of $\operatorname{van} Y_{D}$ in the vancomycin-resistance operon presumably ensures high levels of vancomycin resistance in VanD strains that may not have a defective D-Ala:D-Ala ligase. Consequently it is unlikely to be involved in normal aspects of peptidoglycan metabolism, including control of the level of cross-linking and/or recycling of peptidoglycan degradation products. The location of the active site on the outside surface of the cytoplasmic membrane suggests that $V_{\text {Van }} \mathrm{D}_{\mathrm{D}}$ is probably involved in removing $\mathrm{D}$-Ala from lipid intermediate II as it emerges through the membrane: this would ensure that vancomycin would not form a complex with lipid intermediate II and inhibit the membrane cycle of reactions of peptidogycan synthesis. This cycle is particularly vulnerable as an antibiotic target, as the pool of $\mathrm{C}_{55}$-lipid carriers is only sufficient to maintain peptidoglycan synthesis for $10-15 \mathrm{~s}$ without continuous recycling of the lipid molecules. If this proves to be the role of $\operatorname{VanY}_{\mathrm{D}}$, it raises the question as to the location of the active sites of VanY and $\operatorname{VanY}_{\mathrm{B}}$, which have previously been assumed to be on the inside surface of the cytoplasmic membrane.

It is surprising that $\operatorname{VanY}_{\mathrm{D}}$, with the motifs of a PBP and without the characteristic motifs present in the VanY and $\operatorname{VanY}_{\mathrm{B}}$ DD-carboxypeptidases or the $\operatorname{VanXY}_{\mathrm{C}}$ DDpeptidase/DD-carboxypeptidase, should nevertheless fulfil the same function. The gene is located in the vanD gene cluster in a comparable position to $\operatorname{van} Y_{B}$ in the vanB cluster, namely downstream of the regulatory genes $v a n R_{D}$ and $v a n S_{D}$ and immediately upstream of van $W$ and the triplet of genes essential for vancomycin resistance $[\operatorname{van} H, \operatorname{van} A(B, D), \operatorname{van} X]$. This evolutionary diversity in arriving at the same solution in solving a problem highlights the ability of bacteria to adapt to potentially lethal situations in different ways.

\section{ACKNOWLEDGEMENTS}

B. C. is grateful to J. Blanchard for helpful discussions. This work was supported in part by a Bristol-Myers Squibb Unrestricted Biomedical Research Grant in Infectious Diseases, and by the Programme de Recherche Fondamentale en Microbiologie, Maladies Infectieuses et Parasitaires from the Ministère de l'Education Nationale, de la Recherche et de la Technologie. B. C. was the recipient of a Fellowship from the Fondation pour la Recherche Médicale. O.H.A. thanks Skipsreder Tom Wilhelmsens stiftelse for a grant. 


\section{REFERENCES}

Arthur, M., Depardieu, F., Snaith, H. A., Reynolds, P. E. \& Courvalin, P. (1994). Contribution of VanY DD-carboxypeptidase to glycopeptide resistance in Enterococcus faecalis by hydrolysis of peptidoglycan precursors. Antimicrob Agents Chemother 38, 1899-1903.

Arthur, M., Reynolds, P. \& Courvalin, P. (1996). Glycopeptide resistance in enterococci. Trends Microbiol 4, 401-407.

Arthur, M., Depardieu, F., Cabanié, L., Reynolds, P. \& Courvalin, P. (1998). Requirement of the VanY and VanX DD-peptidases for glycopeptide resistance in enterococci. Mol Microbiol 31, 819-830.

Bugg, T. D. H., Wright, G. D., Dutka-Malen, S., Arthur, M., Courvalin, P. \& Walsh, C. (1991). Molecular basis for vancomycin resistance in Enterococcus faecium BM4147: biosynthesis of a depsipeptide peptidoglycan precursor by vancomycin resistance proteins VanH and VanA. Biochemistry 30, 10408-10415.

Casadewall, B. \& Courvalin, P. (1999). Characterization of the vanD glycopeptide resistance gene cluster from Enterococcus faecium BM4339. J Bacteriol 181, 3644-3648.

Casadewall, B., Reynolds, P. \& Courvalin, P. (2001). Studies of the regulation of expression of the vanD glycopeptide resistance gene cluster from Enterococcus faecium BM4339. J Bacteriol 183, 3436-3446.

Cooper, P. D. (1956). Site of action of radiopenicillin. Bacteriol Rev 20, 28-48.

Gutmann, L., al-Obeid, S., Billot-Klein, D., Guerrier, M. L. \& Collatz, E. (1994). Synergy and resistance to synergy between beta-lactam antibiotics and glycopeptides against glycopeptideresistant strains of Enterococcus faecium. Antimicrob Agents Chemother 38, 824-829.

Joris, B., Ghuysen, J. M., Dive, G. \& 8 other authors (1988). The active-site-serine penicillin-recognizing enzymes as members of the Streptomyces R61 DD-peptidase family. Biochem J 250, 313-324.

Laemmli, U. K. (1970). Cleavage of structural proteins during the assembly of the head of bacteriophage T4. Nature 227, 680-685.
Messer, J. \& Reynolds, P. E. (1992). Modified peptidoglycan precursors produced by glycopeptide-resistant enterococci. FEMS Microbiol Lett 94, 195-200.

Nagarajan, R. (1991). Antibacterial activities and modes of action of vancomycin and related glycopeptides. Antimicrob Agents Chemother 35, 605-609.

Périchon, B., Reynolds, P. \& Courvalin, P. (1997). VanD-type glycopeptide-resistant Enterococcus faecium BM4339. Antimicrob Agents Chemother 41, 2016-2018.

Périchon, B., Casadewall, B., Reynolds, P. \& Courvalin, P. (2000). Glycopeptide-resistant Enterococcus faecium BM4416 is a VanDtype strain with an impaired D-alanine:D-alanine ligase. Antimicrob Agents Chemother 44, 1346-1348.

Rasmussen, J. R. \& Strominger, J. L. (1978). Utilization of a depsipeptide substrate for trapping acyl-enzyme intermediates of penicillin-sensitive D-alanine carboxypeptidases. Proc Natl Acad Sci US A 75, 84-88.

Reynolds, P. E. (1989). Structure, biochemistry and mechanism of action of glycopeptide antibiotics. Eur J Clin Microbiol Infect Dis 8, 943-950.

Reynolds, P. E. (1998). Control of peptidoglycan synthesis in vancomycin-resistant enterococci: D,D-peptidases and D,Dcarboxypeptidases. Cell Mol Life Sci 54, 325-331.

Reynolds, P. E., Arias, C. A. \& Courvalin, P. (1999). Gene vanXY encodes D,D-dipeptidase (VanX) and D,D-carboxypeptidase (VanY) activities in vancomycin-resistant Enterococcus gallinarum BM4174. Mol Microbiol 34, 341-349.

Somner, E. A. \& Reynolds, P. E. (1990). Inhibition of peptidoglycan biosynthesis by ramoplanin. Antimicrob Agents Chemother 34, 413-419.

Wright, G. D., Molinas, C., Arthur, M., Courvalin, P. \& Walsh, C. T. (1992). Characterization of VanY: a D,D-carboxypeptidase from vancomycin-resistant Enterococcus faecium BM4147. Antimicrob Agents Chemother 36, 1514-1518.

Received 15 December 2000; revised 4 June 2001; accepted 8 June 2001. 